\title{
الحملة الإتتخابية في الجزائر بين قانونية الممارسة والتطبيق
}

$$
\begin{aligned}
& \text { شعيبي عبد الجبار } \\
& \text { كلية الحقوق } \\
& \text { جامعة الإخوة منتوري } \\
& \text { قسنطينة }
\end{aligned}
$$

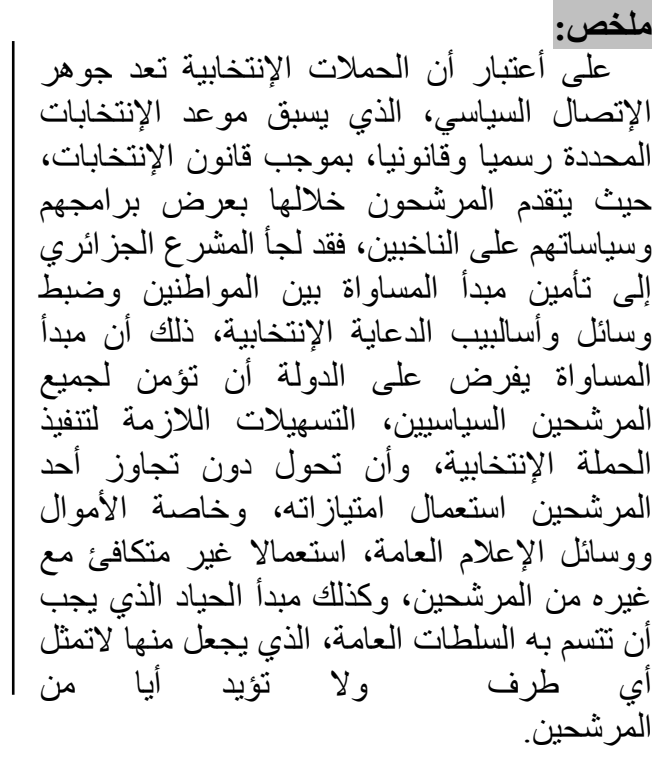

مقدمة: أصبحث الديموقراطية و الحرص ملمبة

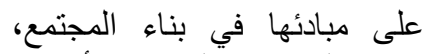
إحدى المعايير و"السمات الأساسية

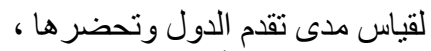

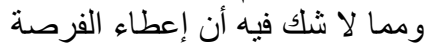

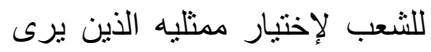

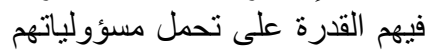

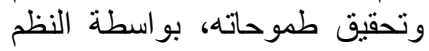

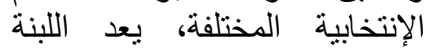

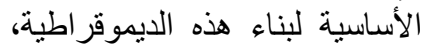
وتدعيم ركائزها الأساسية، و وعليه

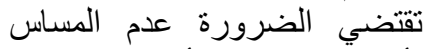
بأي شكل من الأشكال، بصدة الصنة وسلامة العملية الإنتخابية من الإنية بدايتها إلى نهايتها.

\begin{abstract}
:
Considering that the election campaign is the background of political communication that precede the elections. The Algerian legislature has made arrangements to ensure equality between citizens and identifying ways of electioneering .This equality imposes the State to ensure to all candidates facilitations necessary for the implementation of the election campaign, and to prevent any overflow that may affect the principle of state neutrality
\end{abstract}




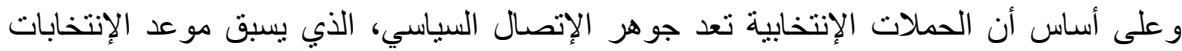

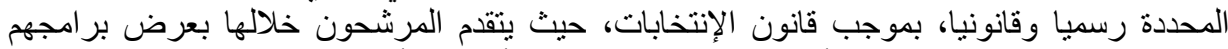

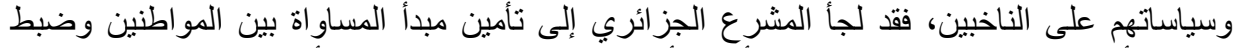

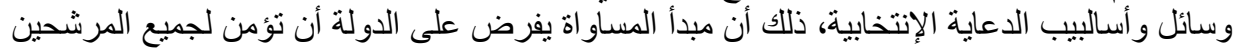

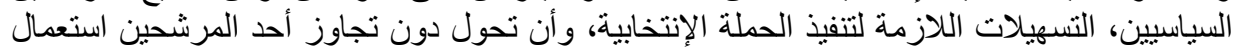

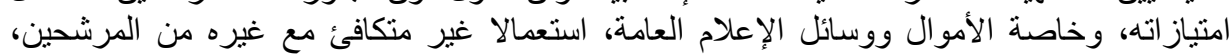

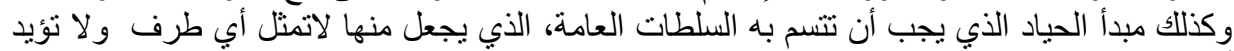

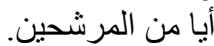

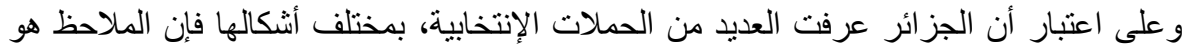

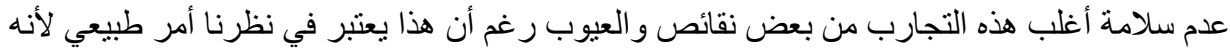

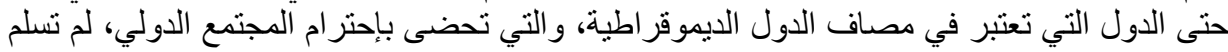

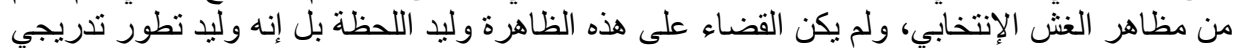

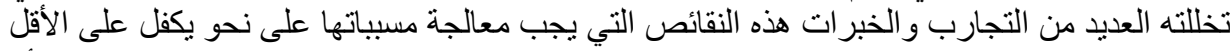

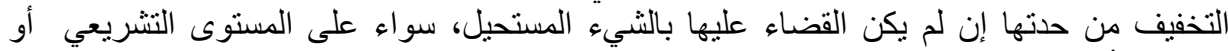

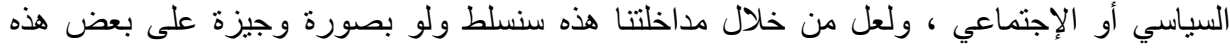

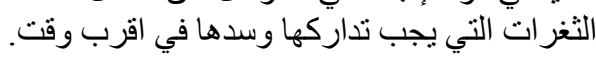

أولا/ مفهوم الحملة الإنتخابية:

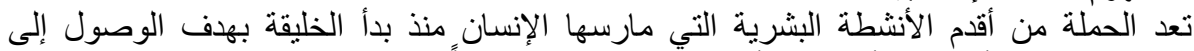

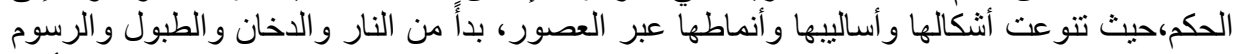

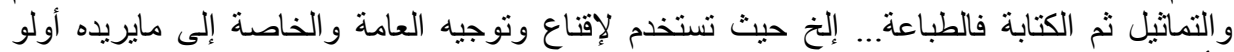

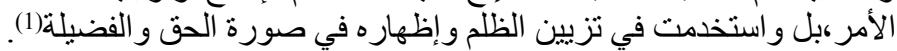

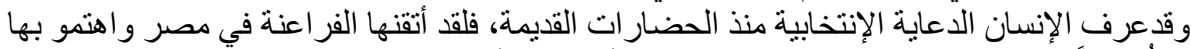

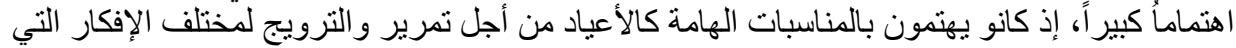

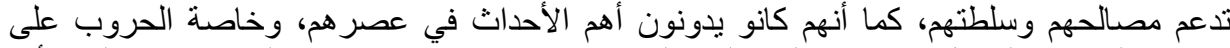

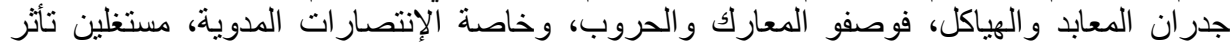
و إعجاب الناس من أجل الترويج للحكم، وكسب ثقة وتأييد العامة،

كما عرفت حضارة بلاد الرافلين هذا النشاط أيضاً، وتبقى الآثار التي عثر عليها العلماء أهم دليل

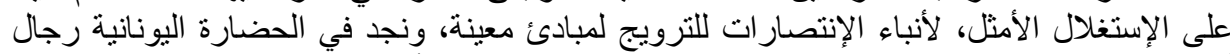

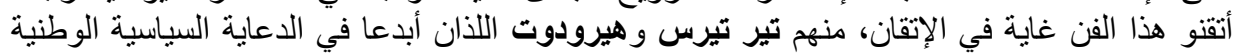

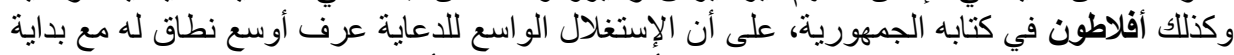

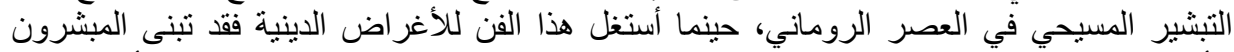

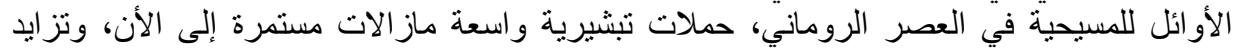

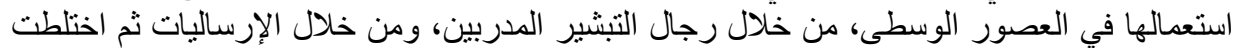
هذه الدعاية ألدينية بالأغراض السياسية، مناصة في الحروب الصليبية.

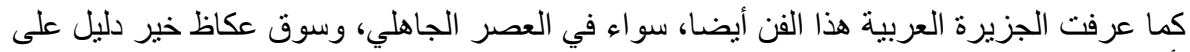

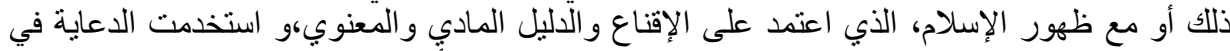

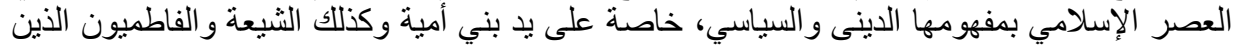


ليعود لهم الفضل في ابتكار وابتداع العديد من الوسائل، ويعد بناء الجامع الأزهر خير دليل على ذلك، إذ إذ إلئ

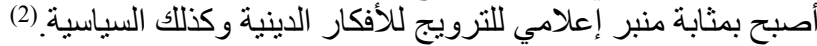

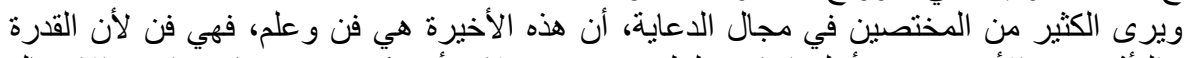

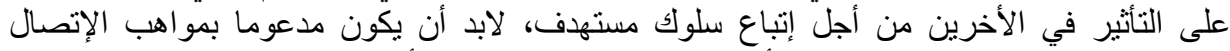

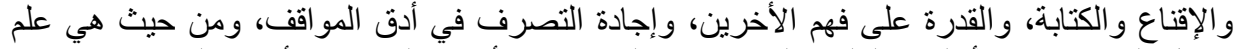

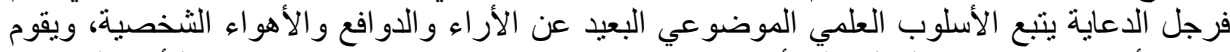

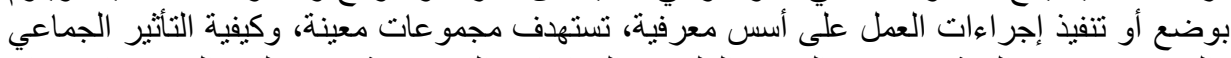

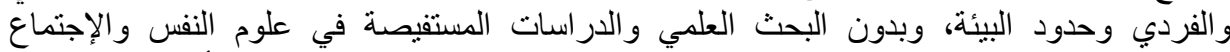

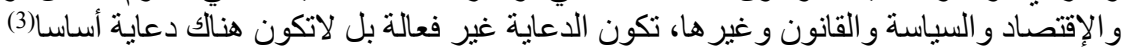

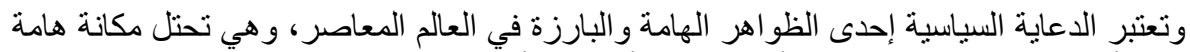

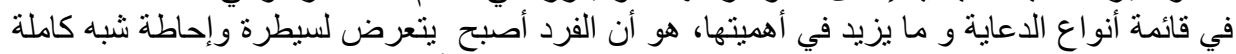

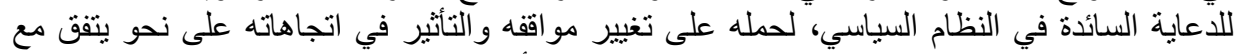

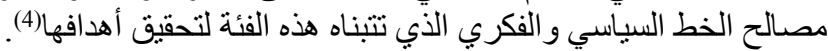

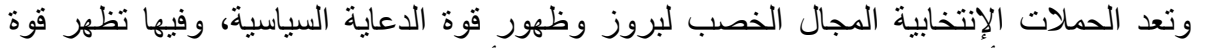

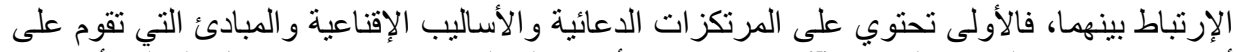

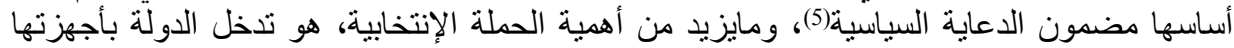

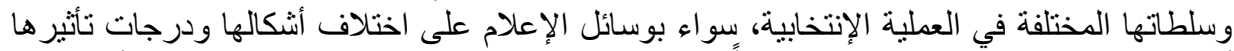

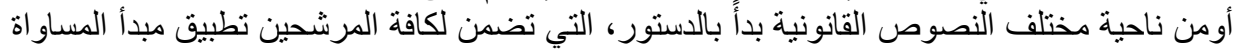

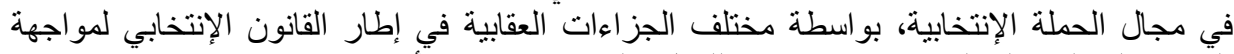

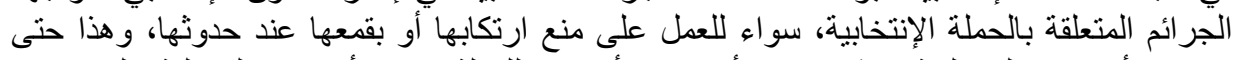

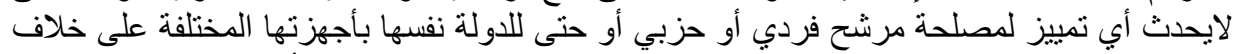

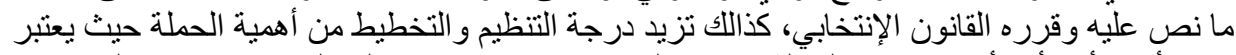

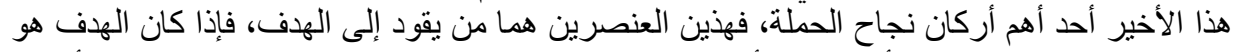

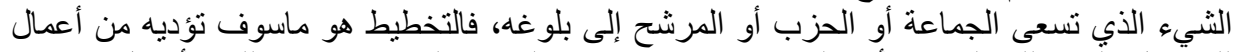

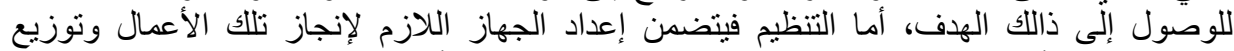

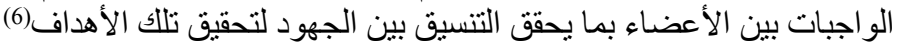

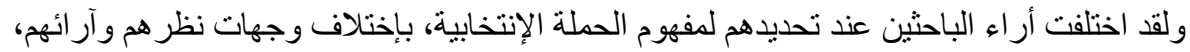

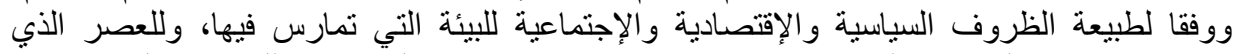

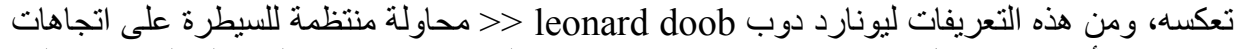

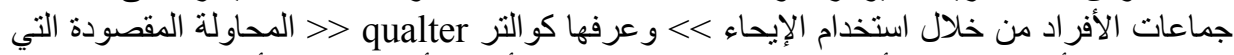

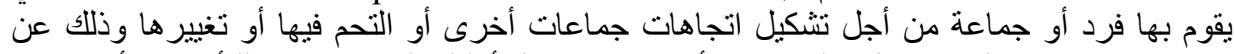

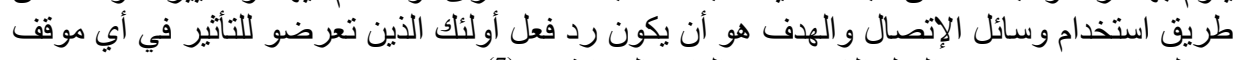

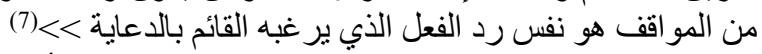

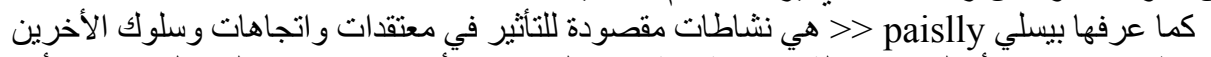

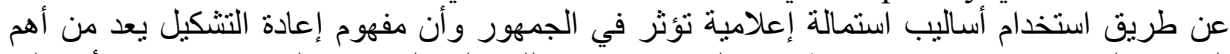

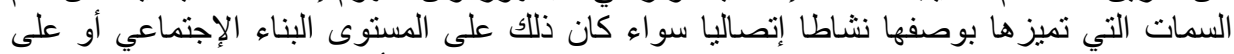

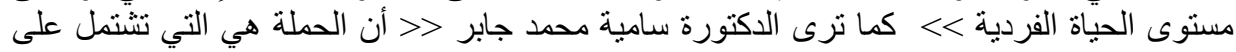

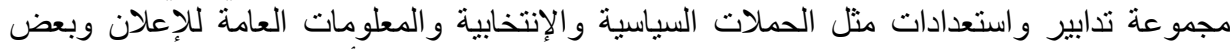
اشكال التعليم واستخدام وسائل الإتصال الجماهيري في البلدان النامية أو في مجال نشر التحدية لإناليدات 
ويكون لها أهداف محددة غالبا ماتكون وجيزة ومكثفة وتستهدف جمهور كبير نسبيا وغالبا ما تعتمد على العى

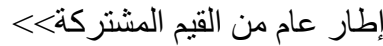

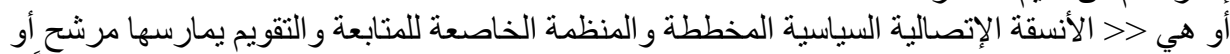

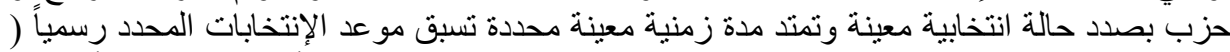

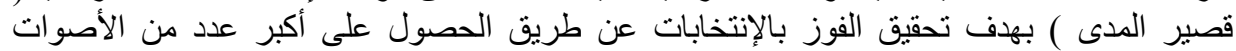

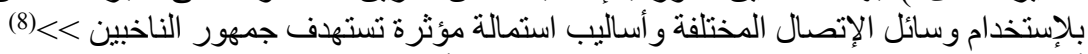

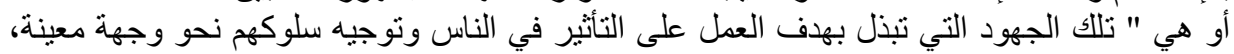

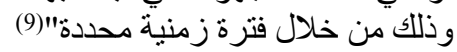

وتتميز الحملات الإنتخابية بعدت خصائص تمنية تميزها عن غيرها من الحملات الإعلامية لكونها حملة

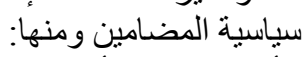

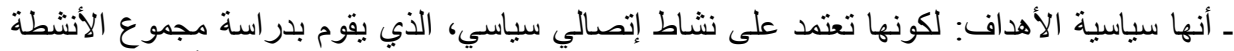

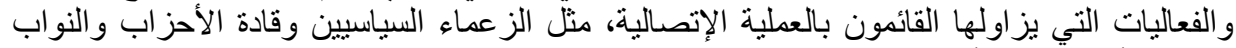

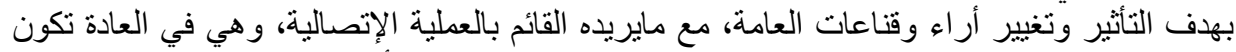

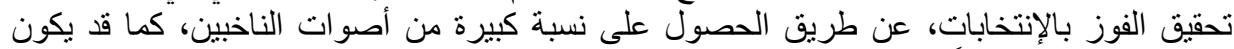

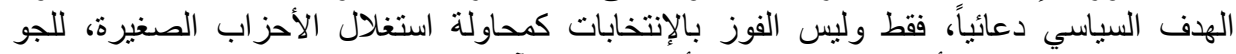

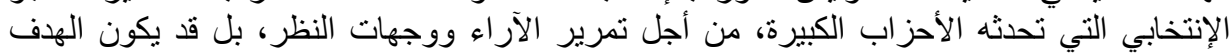

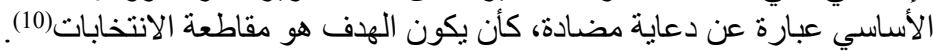

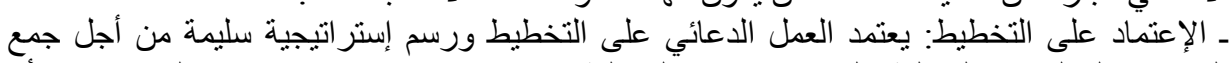

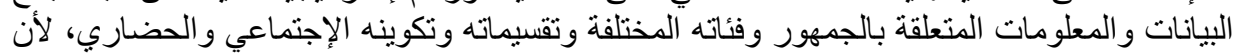
كل فئة إجتماعية لها مشاكلها الخاصة وطريقة بالجهور وفئة تفهم قضاياها العامة.

ــ إستخدام كافة وسائل الأتصال: وسائل الدعاية أحد الأركان الأساسية لنجاحها، وتعد وسائل الإعلام

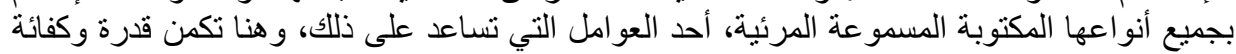

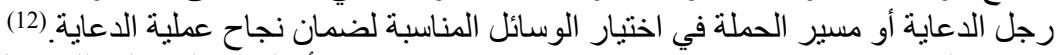

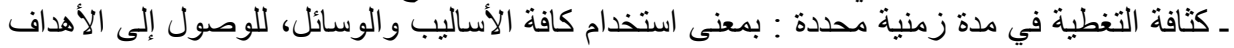

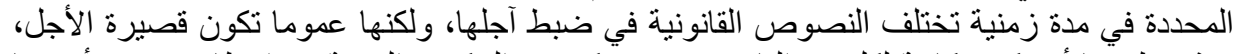

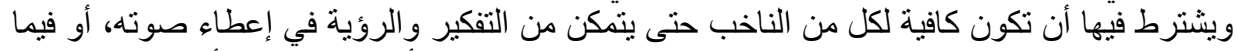

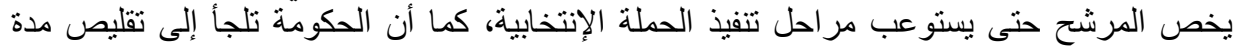

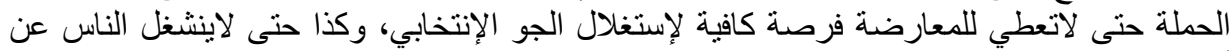

أعمالهم و ون الإنتاج بصفة عامة.

\section{ثانيا/ أثكال الحملات الإنتخابية في الجزائر وخصائصها}

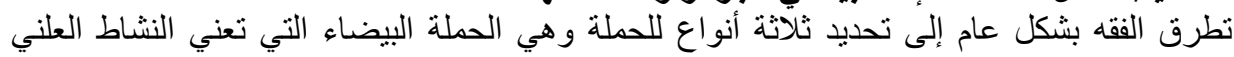

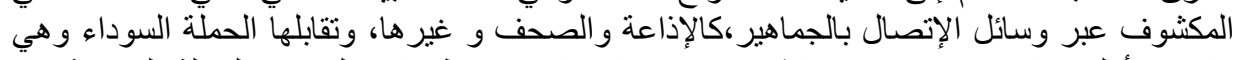

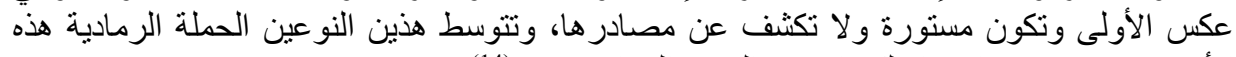

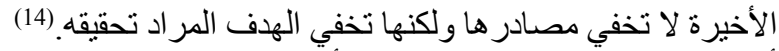

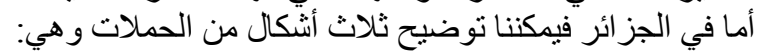

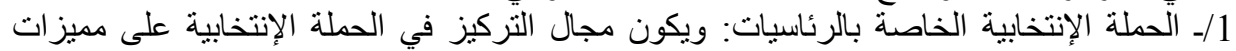

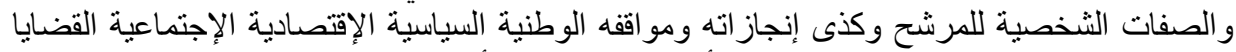

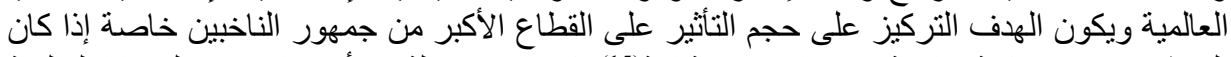
المرشح يتمتع بجاذبية خاصة وخصائص إستثنائية(15)، كمو القفه في الثورة أو مو القفه من القضايا العالمية الثية 
و غبر ها، وعموما يمكن القول أن الحملة الإنتخابية في الرئاسيات الجز ائرية تتميز بتركيز ها على إعطاء

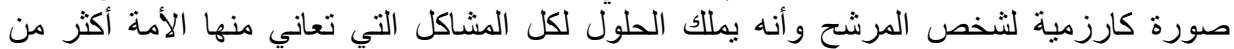

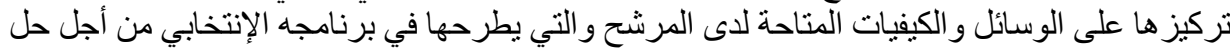

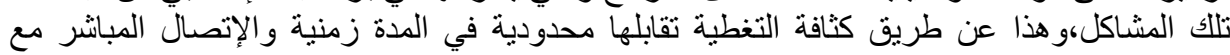

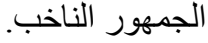

2/ الحملات الإنتخابية الخاصة بالإنتخابات النيابية: ويكون التركيز فيها على سير الحملة الإنتخابية على الإنى

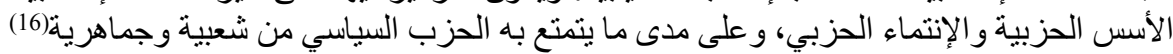

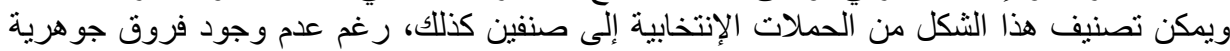

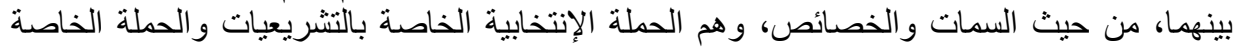
بالإنتخابات المحلية الو لائية والبلدية.

3/ الحملات الإنتخابية الإستفتائية: وتكون الحملة الإنتخابية مركزة على قضية معينة، برزت أهميتها

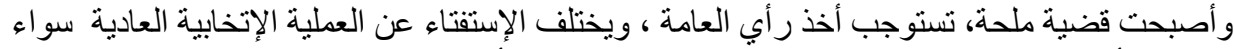

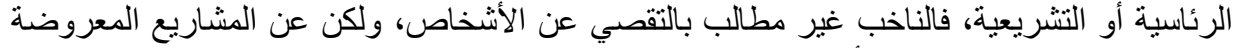

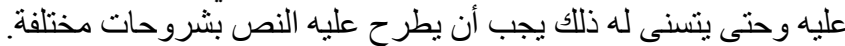

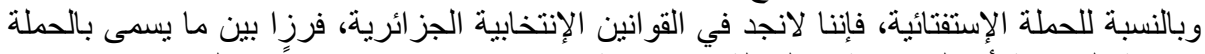

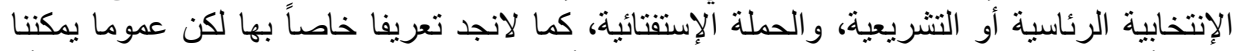

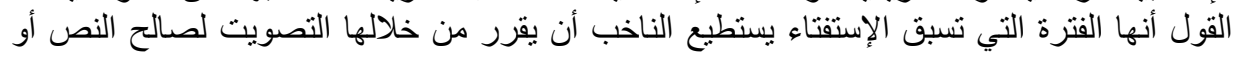

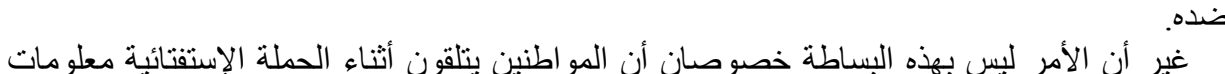

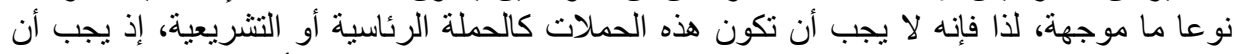

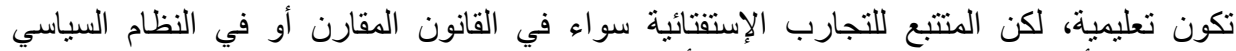

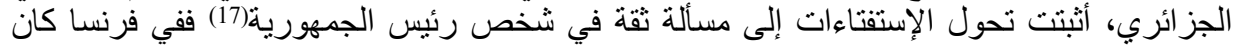

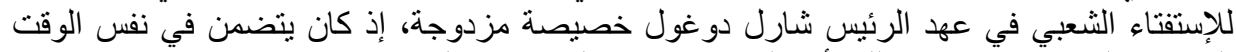

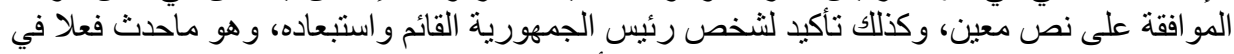

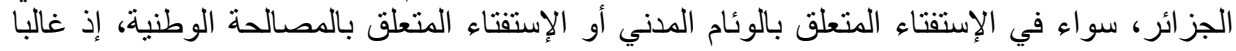

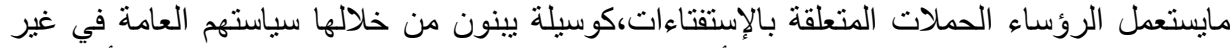

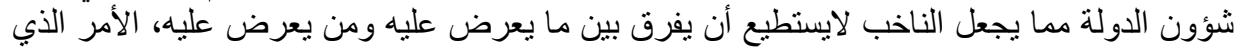

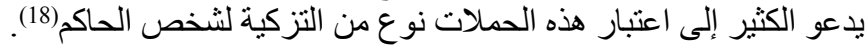

ثنالثار الرقابة على سير الحملة الإتخابية:

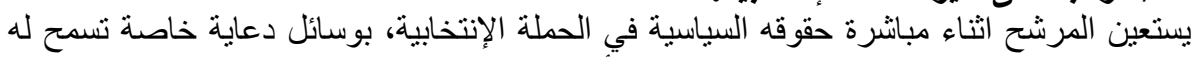

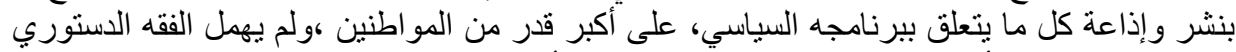

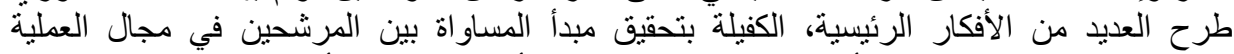

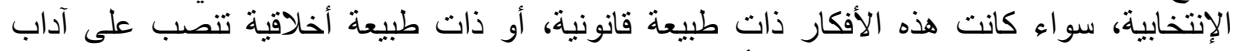

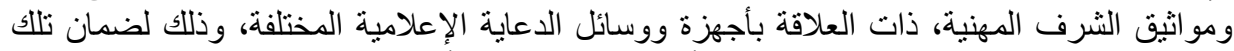

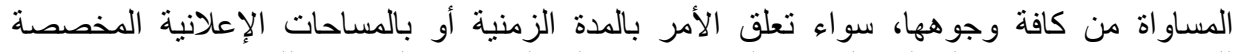

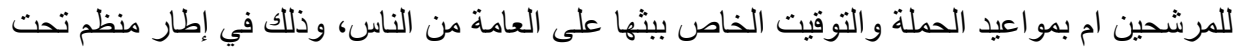
المسؤولية الكاملة لكافة الأشخاص والأحز اب و الأفر اد المعنيين بتللك الدعاية الكاية 
وما يهمنا في هذا الإطار هو إلقاء الضوء على الوسائل التشريعية المستخدمة لتحقيق مبدأ المساواة في مجال العملية الإنتخابية، نلك التي حرصت النظمة الإلتاء الإنتخاب على تحديد معايير ها المنظبطة وأحكام المسؤولية عنها.

لقد عنى القانون العضوي 07/97 المتعلق بالإنتخابات(19)وكذا قانون العقوبات لسيما في المو اد من 126

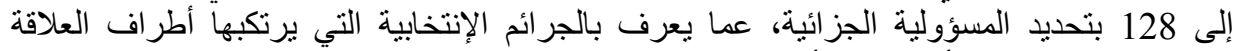

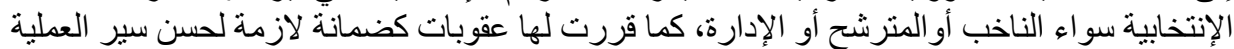

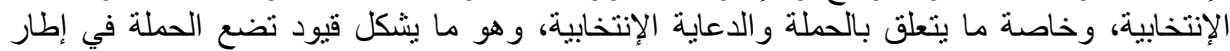
قانوني لايجوز الخروج عنه ومن هذه القيود:

1/.ـ القيود المتعلقة بالضوابط الزمنية للحملة الإنتخابية: من أجل ضمان حسن سير العملية الإنتخابية

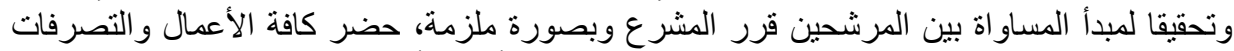

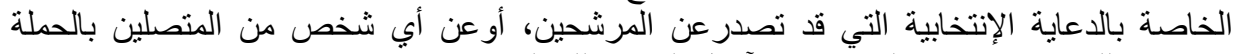

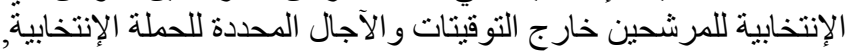

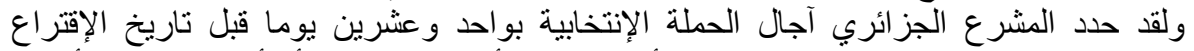

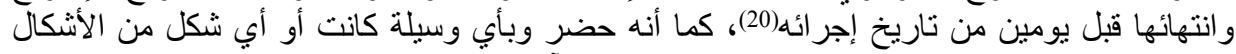

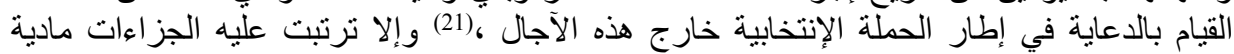

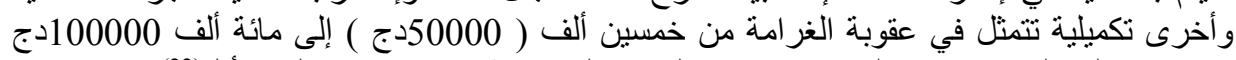

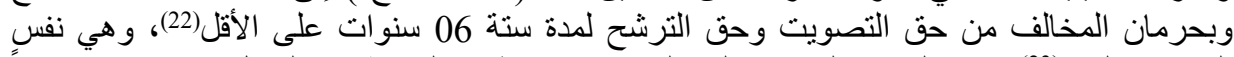

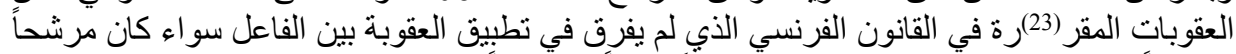

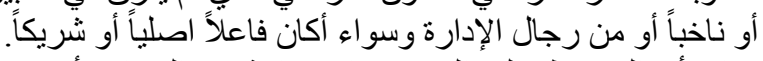

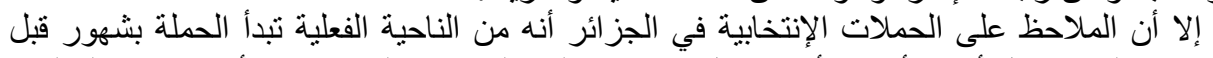

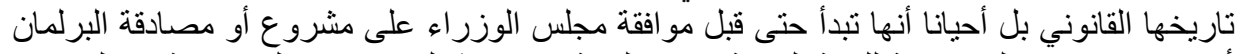

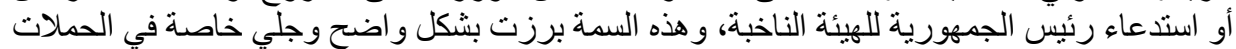

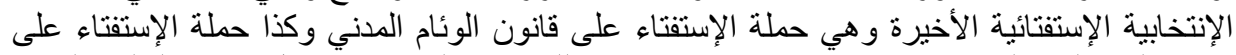

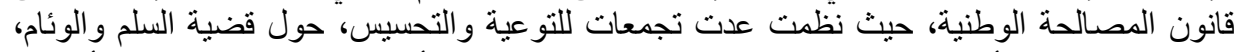

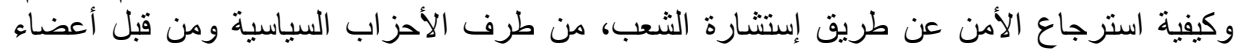

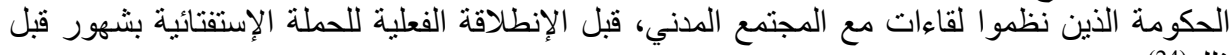

2/2- القيود الخاصة بوسائل الحملة وأهدافها:

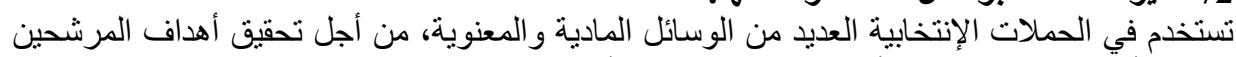

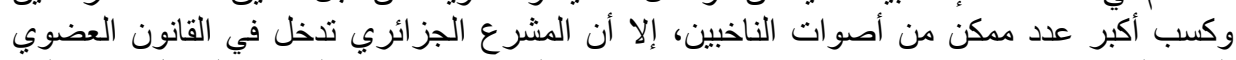

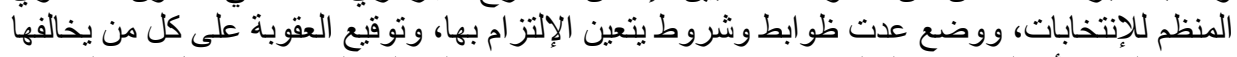

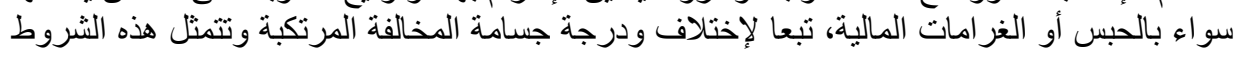

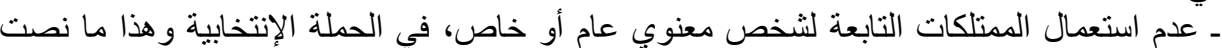

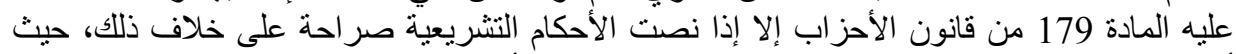

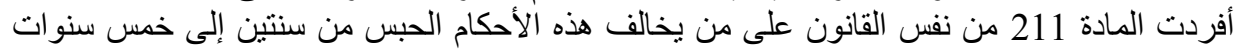

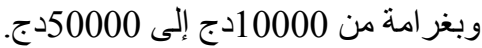

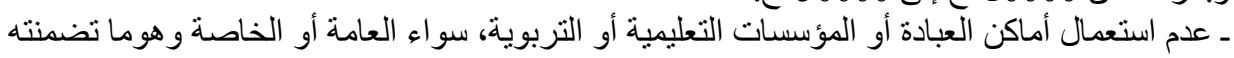

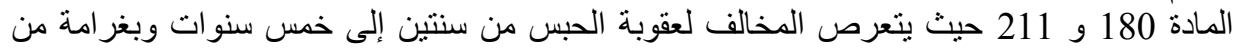
10000دج إلى 50000دج، إلا أن الملاحظ هو وجود مخالفات لنص هذه المادة حيث استعملت العديد 
من الممتلكات العامة في الحملات الإنتخابية ولعل أبرز هذه المخالفات هو استعمال الملصقات في

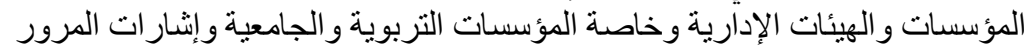

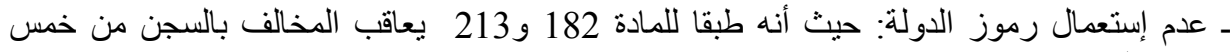

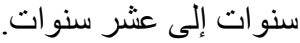

3/ـ القيود المتعلقة بواجب الحياد والأمانة: بموجب نص المادة 181>> يجب على كل مل مترشح أن يمتنع

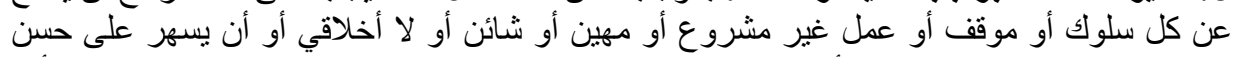

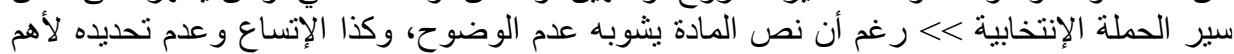

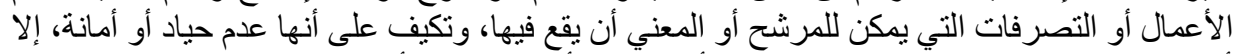

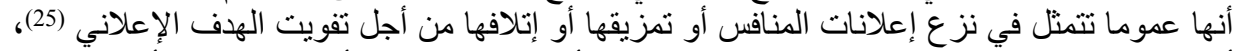

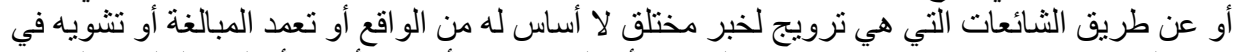

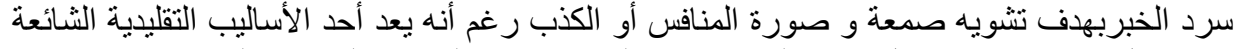

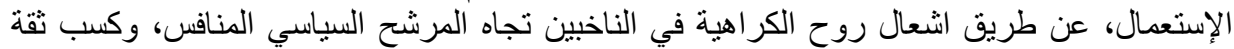
الناخبين عن طريق اختر اع معلومات و وهبة أو الإيحاء بواء بوجودها.

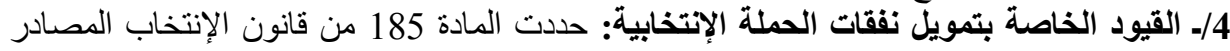

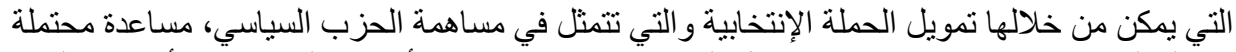

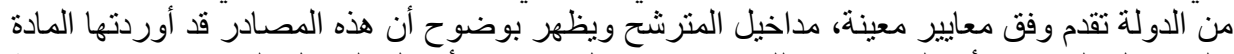

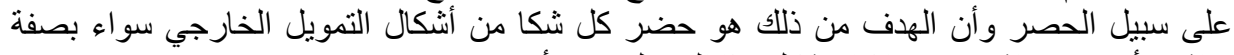
مباشرة أو غير مباشرة ومهما كان شكل هذا التمويل نقدي أو عيني.

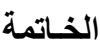

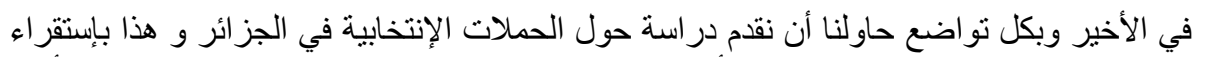

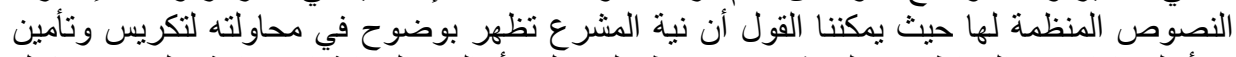

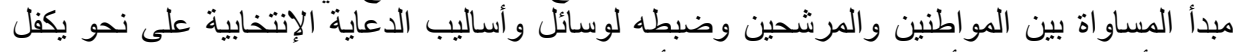

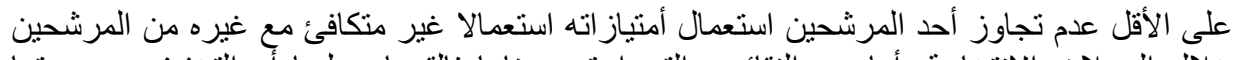

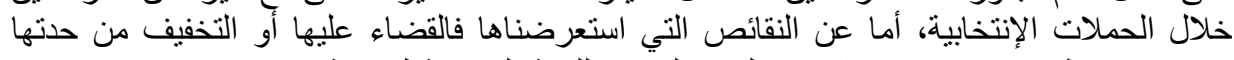

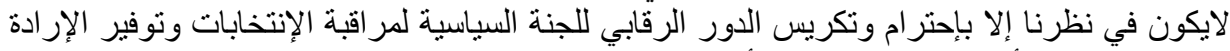

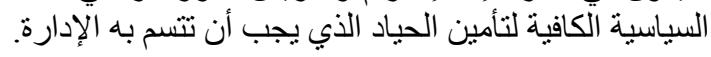



1ـ محمد بوطرفاس، الحملات الإنتخابية ،در اسة مقارنة بين التثريع الجز ائري و التثريع الفرنسي، أطروحة دكتور اه غير منشورة، كلية الحقوق، جامعة قسنطينة، الجزائر سنة المناقثة النّة 2011/ 2012 84 صن 84

2ـ محمد منير حجاب،الدعاية السياسية وتطبيقاته قديما وحديثا، دار الفجر للنشر و التوزيع، الطبعة

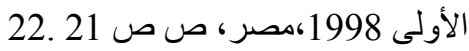

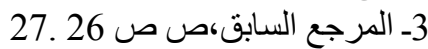
4ـ صفوت العالم، الإتصال السياسي و الدعاية الإنتخابية، دار النهظة العربية، مصر ، 2005،ص27

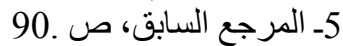
6ـ بشير العلاق، أسس الإدارة الحديثة، دار البازوزي العلمية للنشر والتوزيع، ط1 ،عمان، 1998، ص

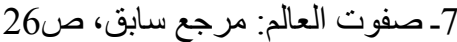
8- زكرياء بن صغير، الحملات الإنتخابية( مفهومها، وسائلها، أساليها )، دار الخلدونية للنشر

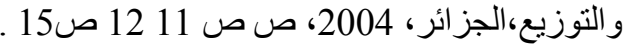

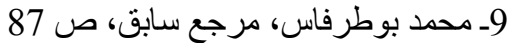

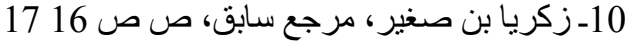

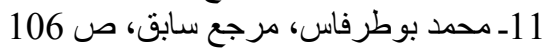

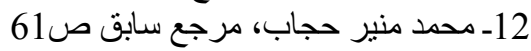

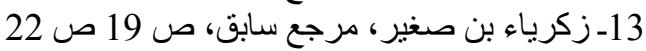

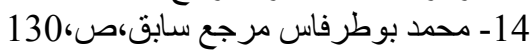

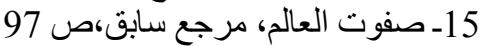

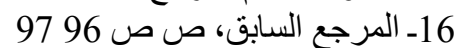

17- لكن هذا لايعني أن هذه الميزة متأصلة في كل التيات التجارب الإستفتائية الجز ائرية.

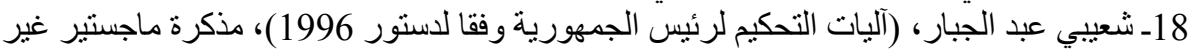

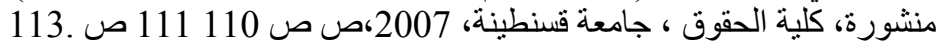

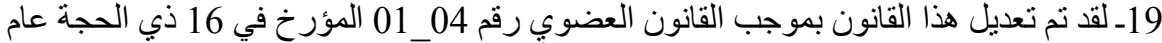

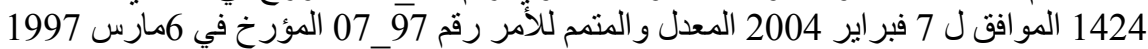
المعدل و المتمم ،المتضمن القانون العضر العنوي المتعلق بالانتخابات

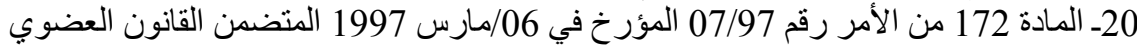

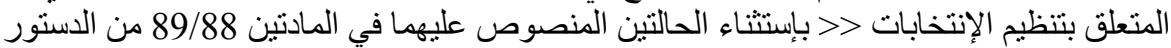

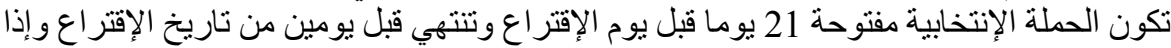

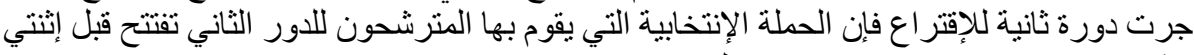

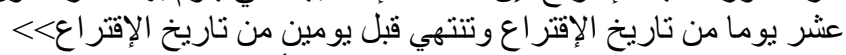

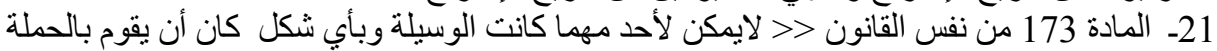

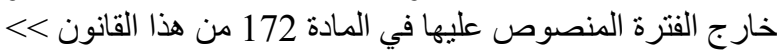

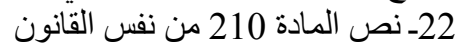

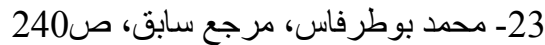

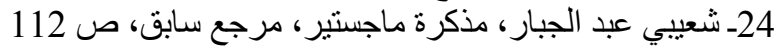

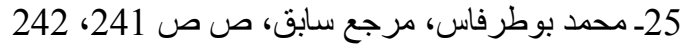

